\title{
Induction of Triple-negative Breast Cancer Cells to Immunogenic Cell Death and Increase Cross-Presentation by Streptomyces sanyensis
}

\author{
Xingguo Quan' ${ }^{1}$ Ji-Young Lee ${ }^{2}$, Jin Hee Park' ${ }^{1}$ Md. Masudul Haque', Hee Yeon Kim³, Ilhwan Kim4, Anbok Lee ${ }^{3}$, \\ II-Whan Choi ${ }^{1}$, SaeGwang Park ${ }^{1, *}$
}

\section{Xingguo Quan ${ }^{1}$, Ji-Young Lee $^{2}$, Jin Hee Park', Md. Masudul Haque', Hee Yeon $\mathrm{Kim}^{3}$, Ilhwan $\mathrm{Kim}^{4}$, Anbok Lee ${ }^{3}$, II-Whan Choi ${ }^{1}$, SaeGwang Park ${ }^{1, *}$}

\section{'Department of Microbiology and Immunology, College of Medicine, Inje University, Busan, SOUTH KOREA. ${ }^{2}$ Department of Internal Medicine, College of Medicine, Inje University, Busan, SOUTH KOREA. \\ ${ }^{3}$ Department of Surgery, College of Medicine, Inje University, Busan, SOUTH KOREA. \\ ${ }^{4}$ Department of Internal Medicine, Division of Oncology Inje University College of Medicine, Haeundae Paik Hospital, Cancer Center, Busan, SOUTH KOREA.}

Correspondence

\section{Prof. SaeGwang Park}

Department of Microbiology and Immunology, College of Medicine, Inje University, Busan 47392 SOUTH KOREA.

Phone no: +82-51-890-6797

Email id: micpsg@inje.ac.kr

\section{History}

- Submission Date: 25-11-2020;

- Review completed: 06-04-2021;

- Accepted Date: 19-05-2021

\section{DOI : 10.5530/pres.13.3.9}

Article Available online http://www.phcogres.com

\section{Copyright}

(c) 2021 Phcog.Net. This is an openaccess article distributed under the terms of the Creative Commons Attribution 4.0 International license.

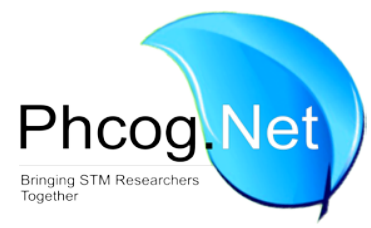

\begin{abstract}
Background: Biomass extract of Streptomyces sanyensis (BE-SS), which is a marine microorganism, has antitumor activity and has white-to-gray aerial mycelium and long chains of long spores in aerial mycelium. Objectives: The anti-cancer effect of BE-SS on triple-negative breast cancer (TNBC) was confirmed and cell death by BE-SS was confirmed to have immunogenicity and whether it could be used for immuno-cancer therapy. Materials and Methods: Human and mouse TNBC cells (MDA-MB-231, HS578T, 4T1-hemagglutinin (HA) and TUBO-P2J-HA cells) were treated with BE-SS at different concentrations for $72 \mathrm{hr}$ and their cytotoxicity was detected using the sulforhodamine B-based (SRB) method. Flow cytometry was used to determine the type of cell death by Annexin V/7-AAD staining and to measure surface exposure to damage-related molecular pattern (DAMP) molecules including calreticulin (CRT), heat shock protein (HSP) 70/90. Carboxyfluorescein succinimidyl ester (CFSE) dilution assay was used to evaluate the immunogenicity of dead cells induced by BE-SS. Results: BE-SS reduced the viability of human (MDA-MB-231 and HS578T-cells) and mouse (4T1-HA and TUBO-P2J-HA cells) breast cancer cells. At $72 \mathrm{~h}$, the $\mathrm{IC}_{50}$ of human and mouse breast cancer cells was $0.02-0.6 \mu \mathrm{g} / \mathrm{ml}$ and $0.005-0.37 \mu \mathrm{g} / \mathrm{ml}$, respectively. BE-SStreated breast cancer cells were positively stained with Annexin V. Surface exposure to DAMP molecules increased in a dose-and time-dependent manner. CFSE dilution analysis showed that dendritic cells (DCs) fed with BE-SS treated breast cancer cells successfully stimulated tumor-specific T-cell proliferation without inhibiting DC function and T-cell proliferation. Conclusion: BE-SS can induce immunogenicity and apoptosis in breast cancer cells and may be a good adjuvant for TNBC immunotherapy.

Key words: Apoptosis, Cross-presentation, DAMPs, Immunogenic cell death, Streptomyces sanyensis, TNBC
\end{abstract}

\section{INTRODUCTION}

Triple-negative breast cancer (TNBC) is characterized by the lack of expression of progesterone receptor, estrogen receptor and human epidermal growth factor receptor-2. TNBC accounts for approximately $15-20 \%$ of breast cancers and its metastasis is strong, disease progression is rapid and survival is relatively poor. In terms of treatment, chemotherapy is currently the only effective systemic therapy for TNBC. However, despite adjuvant chemotherapy, most TNBC patients have a high probability of recurrence within 1-2 years and $<30 \%$ of patients survive for 5 years ${ }^{[1]}$ Notably, TNBC was found to be immunogenic, which makes it a good candidate for immunotherapy. ${ }^{[2]}$ Indeed, immunotherapy has shown great potential in the latest research of TNBC and some clinical studies have shown that immunotherapy has great potential in improving the clinical outcome of patients with this tumor. ${ }^{[3]}$ Although significant clinical progress has been made in the application of immunotherapy, the limitations of this treatment strategy are inevitable; ${ }^{[4]}$ hence, there is an urgent need to identify a substance that can overcome the limitations of immunotherapy and enhance antitumor response.

A recent study reported that compounds extracted from marine microorganisms have potential in drug development, especially mangrove ecosystems, which have attracted increasing attention from the scientific community. In particular, the high biodiversity of mangrove ecosystems and the feasibility of collecting samples have attracted the attention of the scientific community ${ }^{[5]}$ In more than 200 kinds of endophytic fungi and more than 2,000 kinds of actinomycetes collected from mangroves, many secondary metabolites exhibiting a variety of pharmacological properties including anticancer, antimicrobial and antiviral properties have been 
identified. ${ }^{[6]}$ Among them, Streptomyces sanyensis (S. sanyensis) isolated from mangrove soil samples produces staurosporine, ${ }^{[7]}$ which exerts antiviral, neuroprotective and strong inhibitory effects on many cancer cells. ${ }^{[8,9]}$ However, there is not much literature on the biomass extract of S. sanyensis (BE-SS) and its anti-tumor property is difficult to convince without evidence.

Currently, chemotherapy is the only effective systemic therapy available for TNBC. However, in anti-cancer treatment, chemotherapy or radiotherapy can cause immunogenic cell death (ICD) ${ }^{[10]} \mathrm{ICD}$ is a form of cell death that leads to the regulatory activation of the immune response. ${ }^{[1]}$ In ICD, apoptosis is activated, leading to the release of damage-related molecular patterns (DAMPs) such as calreticulin (CRT), adenosine triphosphate (ATP), heat shock protein (HSP) 70/90 and high-mobility group box 1 (HMGB1), which are exposed or released on the cell surface or extracellular. ${ }^{[12,13]}$ These DAMPs activate dendritic cells (DCs), thereby stimulating and enhancing the cross-presentation of tumor antigens to cytotoxic T-cells, ${ }^{[14,15]}$ consequently inhibiting the growth of tumor cells. In this study, we confirmed the antitumor effect of BE-SS on TNBC. Research data show that BE-SS induces apoptosis in breast cancer cells, increases expression of the ICD markers CRT and HSP70/90 and enhances cross-presentation of tumor antigens.

\section{MATERIALS AND METHODS}

\section{Reagents and chemicals}

The National Marine Biological Resources Museum of Korea (SNC087) provided BE-SS. The soil samples were heated in an oven at $120^{\circ} \mathrm{C}$ for $60 \mathrm{~min}$, treated with chloramine-T $(1.0 \%, \mathrm{w} / \mathrm{v})$ solution, ${ }^{[16]}$ and then incubated at $28^{\circ} \mathrm{C}$ for 20 days. Next, on the separation plate, the glucose-aspartic acid-vitamin medium was separated. ${ }^{[17]}$ The extract was then purified, air-dried and ground with a mortar and pestle. ${ }^{[18]}$ The antibodies we used anti-CRT (Cell Signaling, USA), anti-HSP70 FITC, anti-HSP90 PE (Abcam, United Kingdom), secondary antibody (Alexa flour 750-conjugated anti-mouse Fc antibody, Abcam, United Kingdom) and anti-CD8 APC (Invitrogen, USA). The Bone marrow dendritic cells (BMDC) were differentiated with recombinant Granulocyte-macrophage colony-stimulating factor (GM-CSF) (R\&D Systems, USA). The hemagglutinin $(\mathrm{HA})_{512-520}$ peptide (IYSTVASSL) was obtained from Peptron (Daejeon, Korea). Human breast cancer cell lines (MDA-MB-231 and HS578T-cells) and mouse breast cancer cell lines 4T1purchased from ATCC (Manassas, Virginia, USA). The TUBO-P2J cell line was established previous study. ${ }^{[19]}$ The Dulbecco's Modified Eagle Medium (DMEM) or Roswell Park Memorial Institute (RPMI) 1640 medium, fetal bovine serum (FBS) and penicillin-streptomycin solution were purchased form Hyclone (Marlborough, USA). The Cytotoxicity assay kit was purchased from Sigma Chemicals Co. (St. Louis, MO, USA). The APC-annexin V apoptosis detection kit from Bio Legend (San Diego, CA, USA).

\section{Cell culture}

Human (MDA-MB-231 and HS578T-cells) and mouse (4T1-HA and TUBO-P2J-HA cells) breast cancer cells, which TNBC cells were cultured in DMEM or RPMI 1640 medium supplemented with $10 \%$ FBS, $100 \mathrm{U} / \mathrm{ml}$ penicillin and $100 \mu \mathrm{g} / \mathrm{ml}$ streptomycin under a humidified atmosphere containing $5 \% \mathrm{CO}_{2}$ at $37^{\circ} \mathrm{C}$ and passaged every 2 days.

\section{Cytotoxicity assay}

Cytotoxicity of BE-SS on human and mouse breast cancer cells were measured with using an in vitro cytotoxicity assay kit that was sulforhodamine B (SRB) assay. Briefly, cells were seeded in 96-well flat-bottom plates at a density of $1-10 \times 10^{3}$ cells/well and treated with various concentrations of BE-SS (MDA-MB-231 cells, $0.1,0.5$ and $1 \mu \mathrm{g} / \mathrm{ml}$;
HS578T-cells, $0.01,0.05$ and $0.5 \mu \mathrm{g} / \mathrm{ml}$; 4T1-HA cells, $0.05,0.5$ and $2 \mu \mathrm{g} / \mathrm{ml}$; TUBO-P2J-HA cells, $0.005,0.01$ and $0.1 \mu \mathrm{g} / \mathrm{ml}$ ) for $72 \mathrm{hr}$ at $37^{\circ} \mathrm{C}$ and then subjected to the SRB assay. Absorbance was measured using a multi-mode microplate reader (Spectra Max, USA) at $565 \mathrm{~nm}$.

\section{APC-Annexin $\mathrm{V}$ and 7-AAD assay}

Cell death type (apoptosis or necrosis) was analyzed using the APC-annexin V apoptosis detection kit. Briefly, the cells were seeded in 6-well plates at a density of $1-10 \times 10^{4}$ cells/well and incubated at $37^{\circ} \mathrm{C}$ overnight. The cells were treated with various concentrations of BE-SS (MDA-MB-231 cells, 0.1, 0.5 and $1 \mu \mathrm{g} / \mathrm{ml}$; HS578T-cells, 0.01, 0.05 and $0.5 \mu \mathrm{g} / \mathrm{ml}$; 4T1-HA cells, $0.05,0.5$ and $2 \mu \mathrm{g} / \mathrm{ml}$; TUBO-P2J-HA cells, $0.005,0.01$ and $0.1 \mu \mathrm{g} / \mathrm{ml}$ ) for $72 \mathrm{~h}$ at $37^{\circ} \mathrm{C}$ and stained with APCannexin $\mathrm{V}$ and 7 -aminoactinomycin $\mathrm{D}$ (7-AAD), after which the cells were incubated for $15 \mathrm{~min}$ at room temperature away from light and analyzed using the FACS Canto II flow cytometer (BD, USA).

\section{Flowcytometry analysis}

The cell surface exposures of CRT, HSP70 and HSP90 were detected using flowcytometry. Briefly, the cells were treated with various concentrations of BE-SS (MDA-MB-231 cells, 0.1, 0.5 and $1 \mu \mathrm{g} / \mathrm{ml}$; HS578T-cells, 0.01, 0.05 and $0.5 \mu \mathrm{g} / \mathrm{ml}$; 4T1-HA cells, $0.05,0.5$ and $2 \mu \mathrm{g} / \mathrm{ml}$; TUBO-P2J-HA cells, $0.005,0.01$ and $0.1 \mu \mathrm{g} / \mathrm{ml}$ ) for $24,48,72 \mathrm{~h}$ at $37^{\circ} \mathrm{C}$ and stained with primary antibody for anti-CRT $(1: 100)$ for $30 \mathrm{~min}$ at $4^{\circ} \mathrm{C}$ and after washing, stained secondary antibody (1:2000). Anti-HSP70 or antiHSP90 were stained 1:100 for $30 \mathrm{~min}$ at $4^{\circ} \mathrm{C}$. Fluorescence was analyzed using the FACS Canto II flow cytometer and Flow Jo software (BD, USA).

\section{Animals}

Adult BALB/c female mice, 6-8 weeks old, were purchased from Nara Biotech (Seoul, Korea). BALB/c CBy. Cg-Thyla Tg (TcraCl4, TcrbCl4) 1Shrm/Shrmj mice were purchased from Jackson Laboratory (Bar Harbor, $\mathrm{ME}$ ), and bred and/or maintained under an individually ventilated cage system and in accordance with the Institutional Animal Care and Use Committee (2019-001), and housed in a specific pathogen-free environment.

\section{Generation of bone marrow - derived DCs}

Bone marrow (BM) cells were isolated from the femurs and tibias of 6-8 weeks old female BALB/c mice. After sacrifice the BALB/c mouse, BM cells were isolated from the femurs and tibias. BM red blood cells (RBCs) were lysed with lysing buffer for $1 \mathrm{~min}$ at room temperature. After washing, the cells were resuspended in RPMI 1640 supplemented with $10 \%$ heat-inactivated FBS, $100 \mathrm{U} / \mathrm{ml}$ penicillin, $100 \mu \mathrm{g} / \mathrm{ml}$ streptomycin and immature bone marrow-derived DCs were differentiated with $10 \mathrm{ng} / \mathrm{ml} \mathrm{GM-CSF}$ in a humidified $5 \% \mathrm{CO}_{2}$ incubator at $37^{\circ} \mathrm{C}$. On day 3, 5, 7 and 9 of cell culture, floating cells were gently removed and fresh, warmed medium with mouse recombinant GM-CSF $(10 \mathrm{ng} / \mathrm{ml})$ was added. On day 10, non-adherent cells were harvested and used for T-cell proliferation assay experiment.

\section{T-cell proliferation assay}

T-cell proliferation was analyzed using the CFSE dilution assay. After sacrifice, splenocytes were isolated from CL4-HA TCR transgenic mice and the cells were labeled with CFSE for $4 \mathrm{~min}$ at $37^{\circ} \mathrm{C}$. CFSE-labeled splenocytes were cultured in the presence of BMDC fed with BE-SStreated cancer cells for $72 \mathrm{hr}$. For T-cell activation, $0.1 \mu \mathrm{g} / \mathrm{ml} \mathrm{HA}_{512-520}$ peptide was used. The cells were harvested and stained with anti-CD8 for $30 \mathrm{~min}$ at $4^{\circ} \mathrm{C}$, analyzed using the FACS Canto II flow cytometer and Flow Jo software. 


\section{Statistical analysis}

Between-group differences were analyzed using unpaired t-test. Error bars represent \pm standard deviation. Data were analyzed using GraphPad Prism (Version 6 for Windows; GraphPad Software; San Diego, CA). Unless specified, $P<0.05,0.01$ and 0.001 have been noted with ${ }^{*}{ }^{* *}$ and ${ }^{* * *}$, respectively. Differences that are not statistically significant have been left unnoted.

\section{RESULTS}

\section{BE-SS exerted cytotoxic effects and induced apoptosis in} TNBC cells

To investigate the cytotoxic effect of BE-SS on human and mouse TNBC cells, the cells were treated with various concentrations of BE-SS $(0,0.0005,0.005,0.01,0.02,0.025,0.05,0.1,0.5,1$ and $2 \mu \mathrm{g} / \mathrm{mL})$ and SRB analysis was used to assess cell viability (Figure 1a). BE-SS reduced the viability of all tested human (MDA-MB-231 and HS578T-cells) and mouse (4T1-HA and TUBO-P2J-HA cells) breast cancer cell lines. The $\mathrm{IC}_{50}$ (half maximum inhibitory concentration) of BE-SS was $0.55 \pm 0.05 \mu \mathrm{g} / \mathrm{ml}$ for MDA-MB-231 cells and $0.03 \pm 0.01 \mu \mathrm{g} / \mathrm{ml}$ for HS578T-cells in human breast cancer cells and $0.32 \pm 0.05 \mu \mathrm{g} / \mathrm{ml}$ for 4T1-HA cells and $0.006 \pm 0.001 \mu \mathrm{g} / \mathrm{ml}$ TUBO-P2J-HA cells in mouse breast cancer cells. Based on the above data, we determined the drug concentration for future experiments. Then, to detect whether the type of cell death induced by BE-SS was apoptosis or necrosis, staining with Annexin $\mathrm{V}$ and 7-AAD was performed. The cells were treated with different concentration of BE-SS (MDA-MB-231 cells: 0.1, 0.5, $1 \mu \mathrm{g} / \mathrm{ml}$, HS578T-cells: $0.01,0.05,0.5 \mu \mathrm{g} / \mathrm{ml}, 4 \mathrm{~T} 1-\mathrm{HA}$ cells: $0.05,0.5,2 \mu \mathrm{g} / \mathrm{ml}$, TUBO-P2J-HA cells: $0.005,0.01,0.1 \mu \mathrm{g} / \mathrm{mL}$ ) for $72 \mathrm{~h}$ and then stained with APC-Annexin V and 7-AAD. The stained cells were analyzed by flow cytometry. Figure $1 \mathrm{~b}$ shows representative dot blots for Annexin $\mathrm{V} / 7$-AAD. The 7-AAD single-stained cells were not detected and most of the stained cells were Annexin V single- or Annexin V and 7-AAD double-stained cells. These data indicate that BE-SS induces apoptosis in human and mouse breast cancer cells. In addition, Annexin V-positive cells increased with the increase in BE-SS dose.

\section{BE-SS induced TNBC cells surface exposure to CRT, HSP70 and HSP90}

To confirm whether the BE-SS-induced cell death was ICD, flow cytometry was used to evaluate the ICD markers CRT, HSP70 and HSP90 exposed on the cell surface. We found that $24 \mathrm{~h}$ after drug treatment, surface exposure to CRT significantly increased compared with the untreated control group and it increased from $24 \mathrm{~h}$ to $72 \mathrm{~h}$, gradually increasing with time $(p<0.01$ and $p<0.001)$ (Figure 2a). Doxorubicin is a powerful ICD inducer. ${ }^{[20]}$ After treatment with doxorubicin, the positive rate of CRT and HSP70/90 exposed on the surface of human and mouse breast cancer cells was greater than $70 \%$ and $25 \%$, respectively, compared with the untreated control group. The aforementioned BE-SS-treated TNBC cells also showed that as the drug concentration gradually increased, surface exposure to CRT, HSP70 and HSP90 also gradually increased $(p<0.05, p<0.01$ and $p<0.001)$ (Figure $2 \mathrm{~b}-2 \mathrm{~d}$ ). According to the above data, although the number of positive cells was less than that in the doxorubicin treatment group, BE-SS induced the exposure of ICD markers on the surface of TNBC cells.

\section{Apoptosis induced by BE-SS-treatment cross- presentation with DC, which increased the proliferation of $\mathrm{CD} 8^{+}$T-cells}

Although the above experimental data indicate the possibility of ICD induced by BE-SS in TNBC cells, this aspect remains unclear.

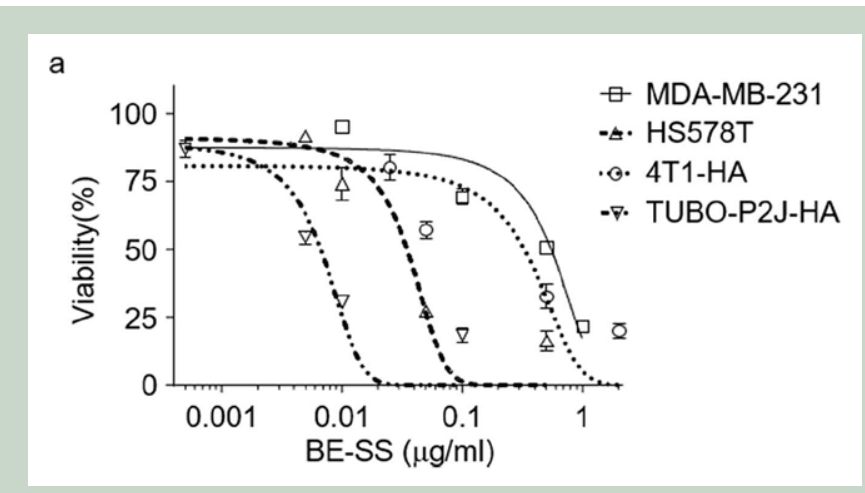

b

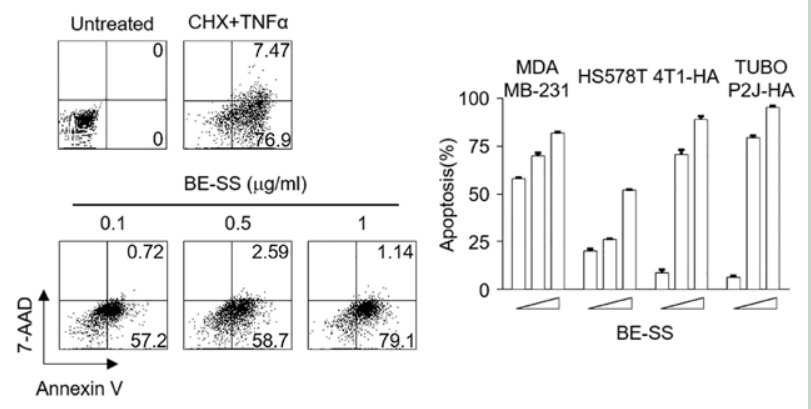

Figure 1: Cell cytotoxicity of the Biomass extract of Streptomyces sanyensis (BE-SS) on TNBC cell lines and induced apoptosis.

(a) Human (MDA-MB-231 and HS578T-cells) and mouse (4T1-HA and TUBO-P2J-HA cells) TNBC cells were treated with the indicated concentrations of $\mathrm{BE}-\mathrm{SS}$ for $72 \mathrm{~h}$ at $37^{\circ} \mathrm{C}$ and cell viability was determined using the SRB assay. (b) Cell death type induced by BE-SS was evaluated with Annexin $V$ and 7-AAD staining. Representative dot plots of Annexin $V$ and 7-AAD staining and apoptosis after human and mouse breast cancer cells were treated with BE-SS (MDA-MB-231 cells: $0.1,0.5,1 \mu \mathrm{g} / \mathrm{ml}$, HS578T-cells: $0.01,0.05,0.5 \mu \mathrm{g} / \mathrm{ml}, 4 T 1-H A$ cells: 0.05 , $0.5,2 \mu \mathrm{g} / \mathrm{ml}$ and TUBO-P2J-HA cells: $0.005,0.01,0.1 \mu \mathrm{g} / \mathrm{ml})$ for $72 \mathrm{~h}$ at $37^{\circ} \mathrm{C}$. Data are presented as mean \pm standard deviation (SD) for triple replicates.

To confirm that BE-SS can induce ICD, a HA antigen-specific CD8 ${ }^{+}$ T-cell proliferation system was recruited to replace the effect on cross-presentation. The detailed design of this system can be found in previously published literature. ${ }^{[21]}$ BMDCs fed with BE-SS-treated 4T1-HA cells induced the proliferation of CL4 mouse T-cells in a dosedependent manner $(p<0.001)$ (Figure $3 a)$. We also confirmed whether BE-SS inhibits the function of DC and T-cells because when BE-SS inhibits the function of DC and T-cells, the potential of BE-SS to induce ICD is meaningless. The experimental design was that BE-SS treatment was applied to feed DCs with necrotic cells or that T-cells were co-cultured with DCs fed with necrotic cells. The DCs fed with necrotic cells successfully stimulated the proliferation of CL4 CD8 ${ }^{+}$T-cells and were not affected by BE-SS treatment (Figure $3 \mathrm{~b}$ ). Upon HA-peptide stimulation, CL4 CD8 ${ }^{+}$T-cells showed approximately $40 \%$ proliferation and they were not affected by BE-SS treatment to change the proliferation rate (Figure $3 \mathrm{c}$ ). These results indicate that BE-SS successfully induced ICD in human and mouse breast cancer cells and had no effect on the function of DC and T-cell stimulation and the proliferation potential of T-cells. 

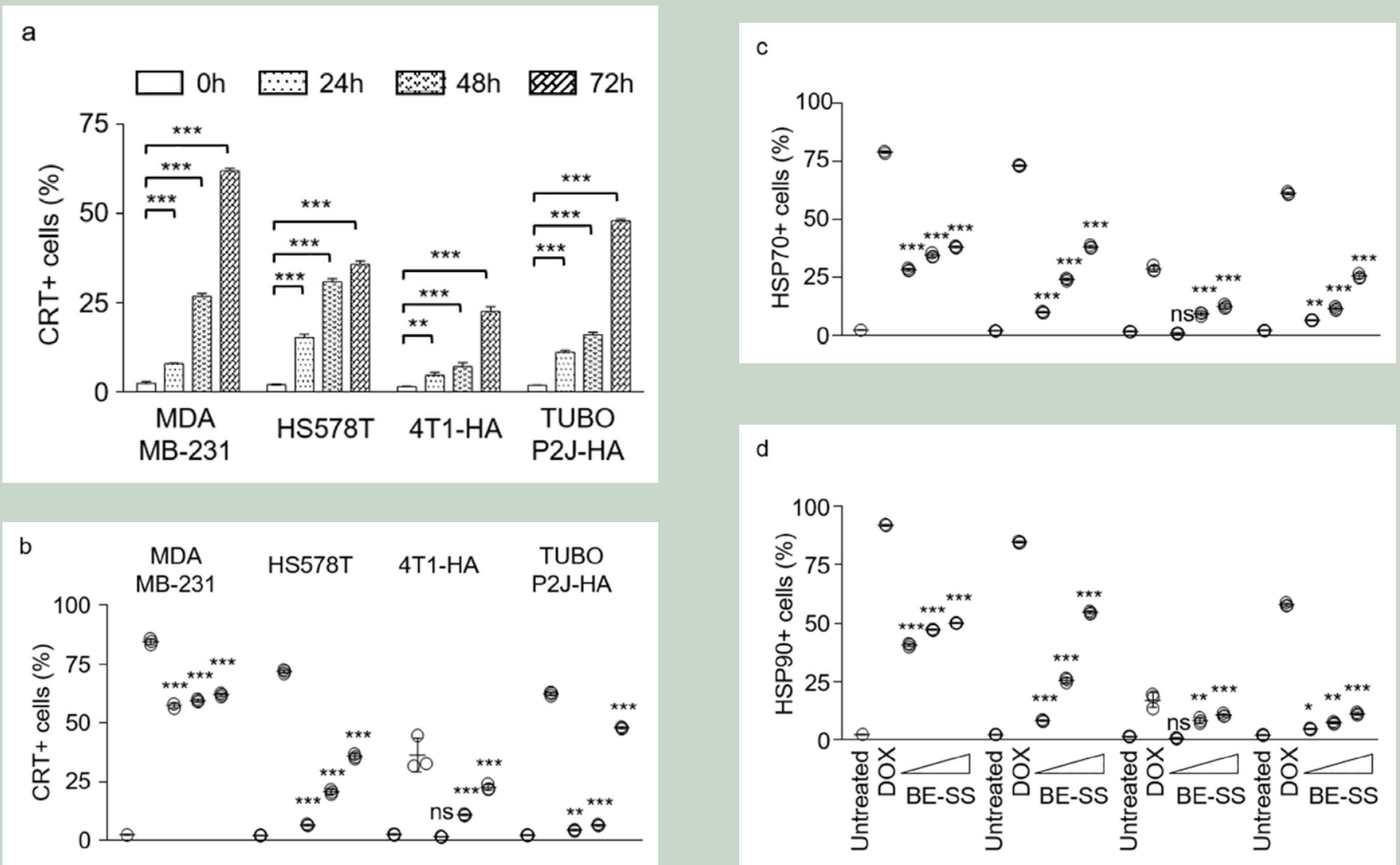

Figure 2: Biomass extract of Streptomyces sanyensis (BE-SS) elicits apoptotic cell's surface to be exposed to CRT, HSP70 and HSP90 on TNBC cells. (a) TNBC cells were treated with the indicated concentrations (MDA-MB-231 cells: $1 \mu \mathrm{g} / \mathrm{ml}, \mathrm{HS} 578 \mathrm{~T}$ cells: $0.5 \mu \mathrm{g} / \mathrm{ml}, 4 \mathrm{~T} 1-\mathrm{HA}$ cells: $2 \mu \mathrm{g} / \mathrm{ml}$ and TUBO-P2JHA cells: $0.1 \mu \mathrm{g} / \mathrm{ml}$ ) of BE-SS for $0,24,48$ and $72 \mathrm{~h}$ at $37^{\circ} \mathrm{C}$ and then stained with anti-CRT and analyzed by flow cytometry. Cells were treated with BE-SS dose-dependently for $72 \mathrm{~h}$ at $37^{\circ} \mathrm{C}$ and then stained with (b) anti-CRT, (c) anti-HSP70 and (d) anti-HSP90 antibodies. They were then analyzed using flow cytometry. Data are presented as mean \pm standard deviation (SD) for triple replicates. ${ }^{*} p<0.05,{ }^{* *} p<0.01,{ }^{* * *} p<0.001$ compared with control.

\section{DISCUSSION}

In this study, we confirmed that BE-SS not only induces ICD in TNBC cells but also enhances cross-presentation of antigens. In this study, we repeatedly emphasized the types of cancer cell death because the proliferation of T-cells is different. It is generally believed that apoptosis does not affect the proliferation of T-cells and necrosis will proliferate T-cells (Figure 3a). ${ }^{[22]}$ However, in this experiment, BE-SS not only induced TNBC cells to apoptosis (Figure 1b) but also promoted T-cell proliferation (Figure 3a). In this way, we must suspect that apoptosis is not simply cell death but a special kind of cell death that is related to necrosis. It is not difficult to find this particular type of death, called necroptosis. ${ }^{[23]}$ This type of cell death is a programmed form of necrosis or inflammatory cell death and has the characteristics of apoptotic and necrotic cell death. ${ }^{[24]}$ This explains our experimental results well; hence, we drew a conclusion that BE-SS-induced breast cancer cell death is not true apoptosis, but necroptosis.

Doxorubicin is a strong ICD inducer and our data show the release of high percentage of CRT, HSP70 and HSP90 (Figure 2b-2d). The ICD maker induced by BE-SS was obviously lower than that induced by doxorubicin (Figure 2). However, doxorubicin is a chemotherapeutic drug that shows great side effects and great damage to the human body. ${ }^{[25]}$ Although there are few reports on BE-SS, it belongs to the compounds of marine microorganisms and they do not cause much harm to the body. ${ }^{[26]}$ Cross-presentation in immunotherapy directly affects the proliferation of $\mathrm{CD}^{+} \mathrm{T}$-cells, ${ }^{[15]}$ and the concept of ICD is closely related to cross-presentation. ${ }^{[12,27,28]}$ Therefore, DAMPs as ICD maker, such as CRT, HSP70 and HSP90, are released from dead cells, which promote the enhancement of cross-presentation, to enhance the proliferation of T-cells. Our experimental data can also be verified. The CD8 ${ }^{+} \mathrm{T}$-cell proliferation rate of doxorubicin was higher than $70 \%$ (Figure 3a). On the contrary, compared with doxorubicin, BE-SS reached only half of it. However, judging from the results, $\mathrm{CD} 8^{+} \mathrm{T}$-cell proliferation rate is still very optimistic. However, for drugs with small side effects and small effects on the body, the results are very optimistic. Our results indicate that the immunogenic cell death induced by BE-SS meets the criteria for inducing ICD. The method of confirming whether to induce ICD has been upgraded from the original gold standard to a faster and easier method of confirming DAMPs. ${ }^{[12,27,28]}$ Although it cannot be used as the main anti-cancer drug, it has a high potential for use as an auxiliary anticancer drug. At present, the monotherapy of chemical drugs cannot meet the requirement for effective treatment of cancer. They are efficient and eliminate tumors completely, but severe cytotoxicity and side effects make it difficult for patients to receive these therapies. But as an emerging adjuvant therapy, ICD can now be an induced artificially now. ${ }^{[12]}$ Although its pharmacological mechanism is not clear, it still has a great research value. 
a
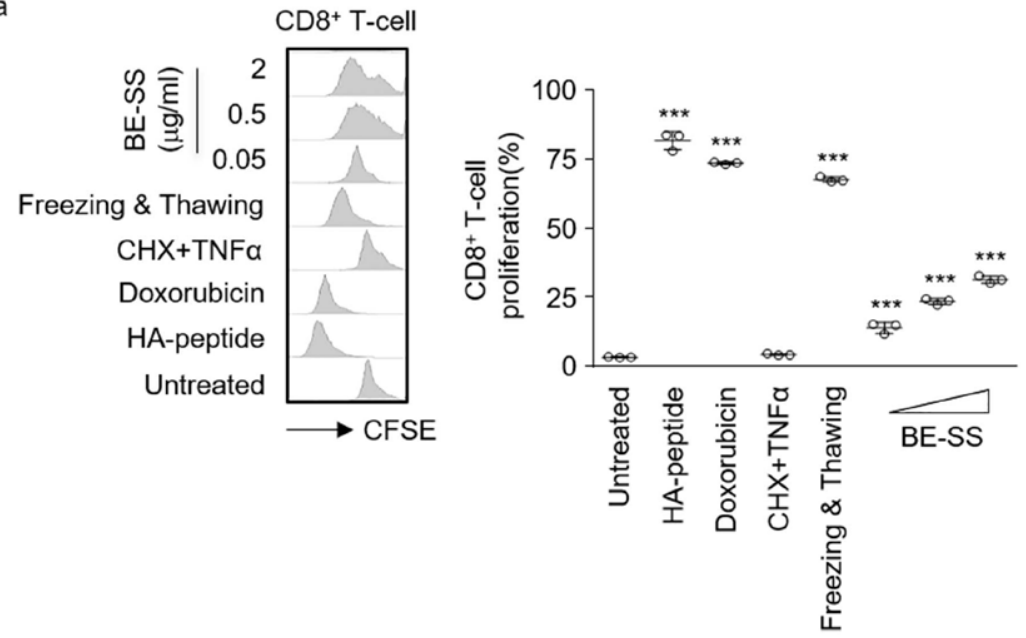

b

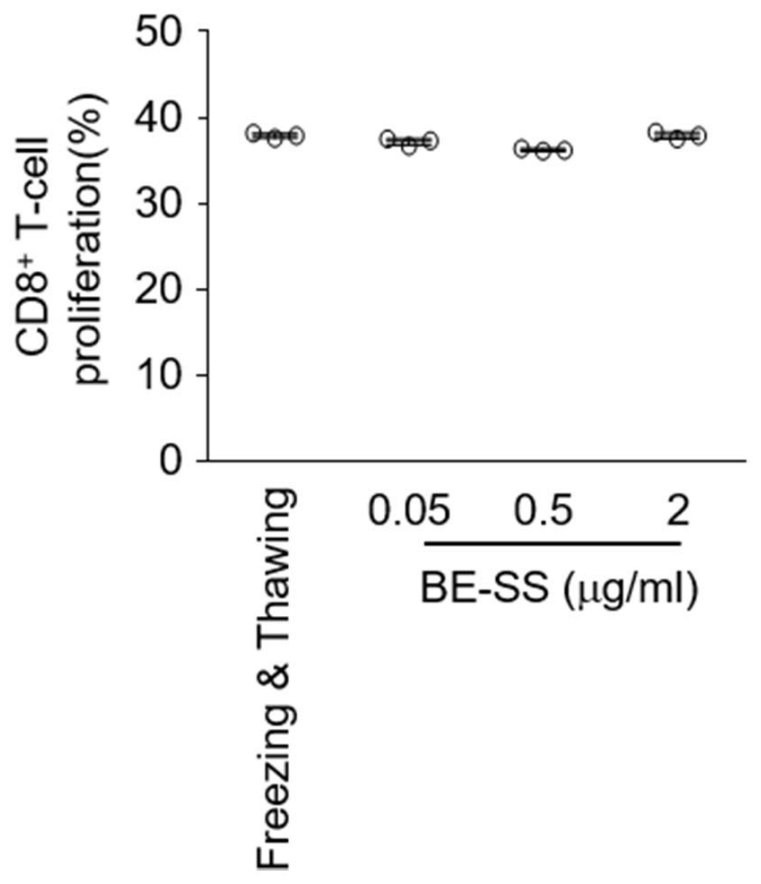

C

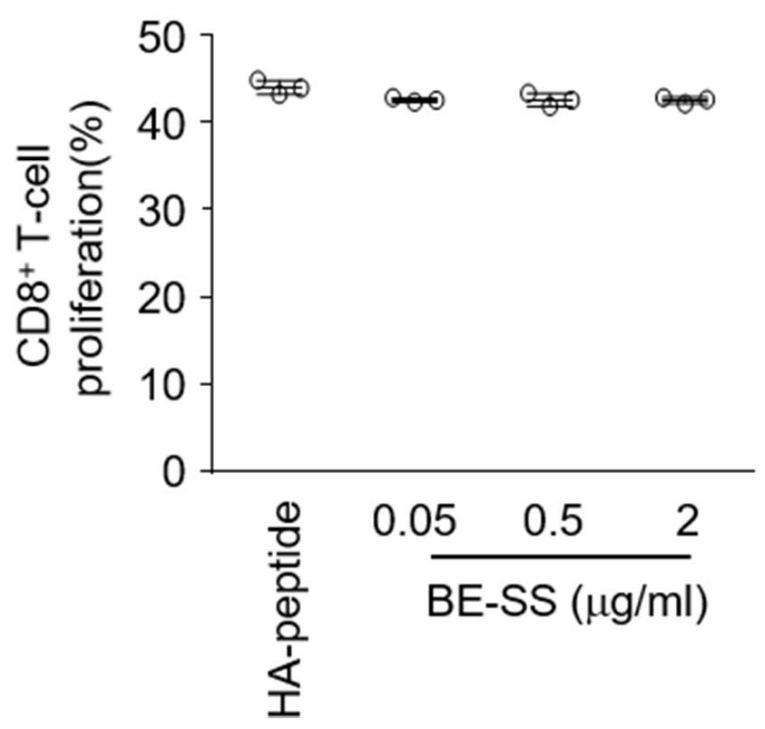

Figure 3: Biomass extract of Streptomyces sanyensis (BE-SS)-treated mouse breast cancer cells can enhance T cell proliferation without inhibiting the function of DCs and T-cell proliferation response.

(a) Representative determination of T-cell proliferation using flow cytometry. CL4 CD8 ${ }^{+}$T-cell proliferation stimulated by DCs treated with BE-SS dosedependently on 4T1-HA cells. (b) BM-derived DCs were fed with necrotic cells that were prepared by freezing three times and then thawing. DCs were treated with BE-SS during feeding of necrotic cells. After feeding, DCs were co-cultured with carboxyfluorescein succinimidyl ester (CFSE)-labeled CL4 splenocytes. (c) CFSE-labelled CL4 splenocytes were stimulated with HA-peptide $(0.2 \mu \mathrm{g} / \mathrm{ml})$ with or without BE-SS. T-cell proliferation was evaluated using flow cytometry. Data are presented as mean \pm standard deviation (SD) for triple replicates. Data are presented as mean \pm standard deviation (SD) for triple replicates. ${ }^{* * *} p<0.001$ compared with control. 


\section{CONCLUSION}

In summary, BE-SS inhibits the growth of TNBC (human and mouse breast cancer) cells, promotes apoptosis and successfully induces ICD. With the increase in time and drug concentration, the CRT, HSP70 and HSP90, indicated by cell surface exposure, also gradually increased, which is an important feature of ICD. We also proved that after BE-SS induces cell death, the dead cell is immunogenic through in vitro crosspresentation experiments. According to our experimental data, BE-SS is a good adjuvant and anticancer drug for TNBC with poor prognosis. However, the pharmacological mechanism and constituents of BE-SS are not clear and the substance that is responsible for the main anti-cancer effect remains to be determined. However, the immunotherapy for TNBC has much potential for clinical application.

\section{ACKNOWLEDGEMENT}

This work was supported by the 2018 Inje University research grant (Grant numbers 2018-0199).

\section{CONFLICT OF INTEREST}

The authors declare that there is no conflict of interest regarding the publication of this paper.

\section{Author Contributions}

Xingguo Quan, Ilhwan Kim, Anbok Lee, Il-Whan Choi and SaeGwang Park designed the study. Xingguo Quan, Ji-Young Lee, Jin Hee Park, Md. Masudul Haque and Hee Yeon Kim collected the data. Xingguo Quan, Jin Hee Park and SaeGwang Park drafted the manuscript. All authors discussed the results and contributed to the final manuscript.

\section{ABBREVIATIONS}

BE-SS: Biomass extract of Streptomyces sanyensis; TNBC: Triple-negative breast cancer; BMDCs: Bone marrow dendritic cells; ICD: immunogenic cell death; DAMP: Damage-related molecular pattern; CRT: Calreticulin; ATP: Adenosine triphosphate; HSP: Heat shock protein; HMGB1: High-mobility group box 1; HA: Hemagglutinin; SRB: Sulforhodamine B-based method; CFSE: Carboxyfluorescein succinimidyl ester; 7-AAD: 7-aminoactinomycin D; GM-CSF: Granulocyte-macrophage colonystimulating factor.

\section{REFERENCES}

1. Dent R, Trudeau M, Pritchard KI, Hanna WM, Kahn HK, Sawka CA, et al. Triple-Negative Breast Cancer: Clinical Features and Patterns of Recurrence. 2007:13(15):4429-34.

2. McArthur HL, Page DB. Immunotherapy for the treatment of breast cancer: checkpoint blockade, cancer vaccines, and future directions in combination immunotherapy. Clinical Advances in Hematology and Oncology: $\mathrm{H} \& \mathrm{O}$. 2016;14(11):922-33

3. Vikas $P$, Borcherding $N$, Zhang $W$. The clinical promise of immunotherapy in triple-negative breast cancer. Cancer Manag Res. 2018;10:6823-33.

4. Cogdill AP, Andrews MC, Wargo JA. Hallmarks of response to immune checkpoint blockade. British Journal of Cancer. 2017;117(1):1-7.
5. Cartuche L, Sifaoui I, Cruz D, Reyes-Batlle M, López-Arencibia A, Javier Fernández J, et al. Staurosporine from Streptomyces sanyensis activates Programmed Cell Death in Acanthamoeba via the mitochondrial pathway and presents low in vitro cytotoxicity levels in a macrophage cell line. Sci Rep. 2019;9(1):11651.

6. Gomes NC, Cleary DF, Calado R, Costa R. Mangrove bacterial richness. Communicative and Integrative Biology. 2011;4(4):419-23.

7. Sui JL, Xu XX, Qu Z, Wang HL, Lin HP, Xie QY, et al. Streptomyces sanyensis sp. nov., isolated from mangrove sediment. International Journal of Systematic and Evolutionary Microbiology. 2011;61(Pt7):1632-7.

8. Omura S, Iwai Y, Hirano A, Nakagawa A, Awaya J, Tsuchya $H$, et al. A new alkaloid AM-2282 OF Streptomyces origin. Taxonomy, fermentation, isolation and preliminary characterization. The Journal of Antibiotics. 1977;30(4):275-82

9. Oka S, Kodama M, Takeda H, Tomizuka N, Suzuki H. Staurosporine, a Potent Platelet Aggregation Inhibitor from a Species. Agricultural and Biological Chemistry. 1986;50(11):2723-7.

10. Zhou J, Wang G, Chen Y, Wang H, Hua Y, Cai Z. Immunogenic cell death in cancer therapy: Present and emerging inducers. Journal of Cellular and Molecular medicine. 2019;23(8):4854-65.

11. Garg AD, Dudek-Peric AM, Romano E, Agostinis P. Immunogenic cell death. The International Journal of Developmental Biology. 2015;59(1-3):131-40.

12. Kroemer G, Galluzzi L, Kepp O, Zitvogel L. Immunogenic Cell Death in Cancer Therapy. Annual Review of Immunology. 2013;31(1):51-72.

13. Kepp O, Senovilla L, Vitale I, Vacchelli E, Adjemian S, Agostinis P, et al. Consensus guidelines for the detection of immunogenic cell death. Oncoimmunology. 2014;3(9):e955691-e.

14. Ogawa M, Tomita Y, Nakamura Y, Lee MJ, Lee S, Tomita S, et al. Immunogenic cancer cell death selectively induced by near infrared photoimmunotherapy initiates host tumor immunity. Oncotarget. 2017:8(6):10425-36.

15. Sánchez-Paulete AR, Teijeira A, Cueto FJ, Garasa S, Pérez-Gracia JL, Sánchez-Arráez A, et al. Antigen cross-presentation and T-cell cross-priming in cancer immunology and immunotherapy. Annals of Oncology. 2017;28:xii44-55.

16. Hayakawa M, lino H, Takeuchi S, Yamazaki T. Application of a method incorporating treatment with chloramine-T for the selective isolation of Streptosporangiaceae from soil. Journal of Fermentation and Bioengineering. 1997;84(6):599-602.

17. Hayakawa M, SadakataT, Kajiura T, Nonomura HJJ. New methods for the highly selective isolation of Micromonospora and Microbispora from soil. Journal of Fermentation and Bioengineering. 1991;72(5):320-6.

18. Gong B, Chen S, Lan W, Huang Y, Zhu X. Antibacterial and Antitumor Potential of Actinomycetes Isolated from Mangrove Soil in the Maowei Sea of the Southern Coast of China. Iran J Pharm Res. 2018;17(4):1339-46.

19. Song H, Kim TO, Ma SY, Park JH, Choi JH, Kim JH, et al. Intratumoral heterogeneity impacts the response to anti-neu antibody therapy. BMC Cancer 2014;14(1):647.

20. Vacchelli E, Aranda F, Eggermont A, Galon J, Sautès-Fridman C, Cremer I, et al Trial Watch: Chemotherapy with immunogenic cell death inducers. Oncoimmunology. 2014;3(1):e27878-e.

21. Quan X, Kwak BS, Lee JY, Park JH, Lee A, KimTH, et al. Induces Immunogenic Cell Death and Enhances Antitumor Immunogenic Response in Breast Cancer Evidence-Based Complementary and Alternative Medicine. 2020;2020:9053274.

22. Maino G, Joris I. Apoptosis, oncosis, and necrosis. An overview of cell death The American Journal of Pathology. 1995;146(1):3-15.

23. Linkermann A, Green DR. Necroptosis. The New England Journal of Medicine. 2014;370(5):455-65

24. Nirmala JG, Lopus M. Cell death mechanisms in eukaryotes. Cell Biology and Toxicology. 2020;36(2):145-64

25. Carvalho C, Santos RX, Cardoso S, Correia S, Oliveira PJ, Santos MS, et al. Doxorubicin: the good, the bad and the ugly effect. Current Medicinal Chemistry. 2009:16(25):3267-85

26. Lindequist U. Marine-Derived Pharmaceuticals - Challenges and Opportunities Biomol Ther. 2016:24(6):561-71.

27. Galluzzi L, Buqué A, Kepp O, Zitvogel L, Kroemer G. Immunogenic cell death in cancer and infectious disease. Nature Reviews Immunology. 2017;17(2):97-111.

28. Kepp O, Senovilla L, Vitale I, Vacchelli E, Adjemian S, Agostinis P, et al. Consensus guidelines for the detection of immunogenic cell death. Oncoimmunology. 2014:3(9):e955691. 
GRAPHICAL ABSTRACT

Biomass extract of Streptomyces sanyensis

Treatment

Triple-negative breast cancer

(MDA-MB-231, HS578T, 4T1-HA and P2J-HA cells)

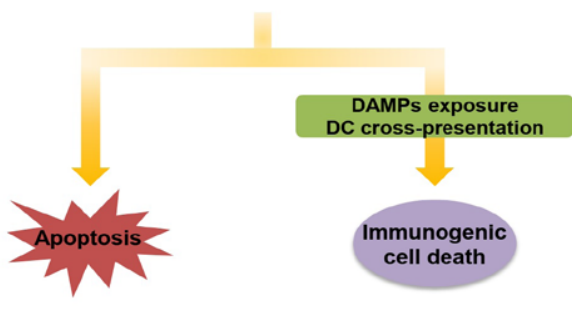

\section{SUMMARY}

- Biomass extract of Streptomyces sanyensis (BE-SS) extracted from marine microorganisms and produces staurosporine which exerts antiviral, neuroprotective and strong inhibitory effects on many cancer cells.

- The $\mathrm{IC}_{50}$ (half maximum inhibitory concentration) of BE-SS was $0.02-0.6 \mu \mathrm{g} / \mathrm{ml}$ for human (MDA-MB-231 and HS578T-cells), $0.005-0.27 \mu \mathrm{g} / \mathrm{ml}$ for mouse (4T1-HA and TUBO-P2J-HA cells) triple-negative breast cancer (TNBC) cells and induced apoptosis.

- Immunogenic cell death (ICD) maker (E.g., calreticulin and heat shock protein 70/90) exposed on the surface of TNBC cells treated by BE-SS.

- $\quad$ TNBC cells treated with BE-SS enhanced dendritic cell (DC) cross-presentation.

- In this study, we confirmed that BE-SS is an ICD inducer.
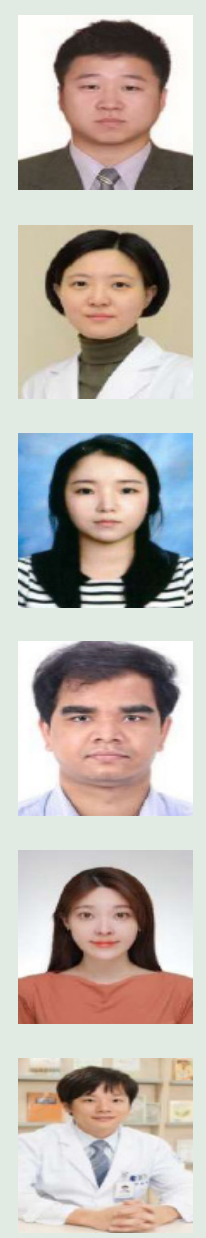

\section{SUMMARY}

Xingguo Quan, is a combined master's and doctoral student at Inje University College of Medicine, majoring in microbiology and immunology. He graduated from Changchun University of Chinese Medicine with a bachelor's degree in clinical medicine. His current research focuses on the impact of immunogenic cell death on immune checkpoint inhibitor therapy in breast cancer.

Ji Young Lee is an Assistant Professor at the Department of Oncology/Hematology, Inje University, School of Medicine, working mainly in solid tumor. Her doctoral research focus on histone deacetylase inhibitor induced immunogenic cell death in breast cancer cells.

Jin Hee Park, PhD is a post-doctoral associate at the College of Medicine, INJE University. Her doctoral research focused on the radiation induced anti-cancer effect by anti-tumor immunity in inter-tumor heterogenous multi-tumor mouse breast cancer model.

Md. Masudul Haque, is a PhD student at Inje University College of Medicine where he graduated in master of science in Microbiology and Immunology. He graduated in bachelor of science in Biochemistry and Molecular Biology from University of Chittagong. His current study focuses on changing tumor microenvironment through effective blocking of adenosinergic signaling pathway.

Hee Yeon Kim M.D is currently under clinical fellowship at Breast Center Surgery department of Inje University, Busan Paik Hospital, South Korea. Her main areas of research include breast cancer treatment, immunology and biomarkers for pre diction of breast cancer prognosis.

Ilhwan Kim is an Associate Professor at the Inje university, College of medicine. He is expert of the medical oncology, especially lung / breast / pancreas-biliary / colorectal cancer. He received his doctorate in medicine from Inje University immune-oncology lab and is currently in charge of treating cancer patients as a clinical doctor at Haeundae Paik Hospital. He is conducting clinical \& basic research for various anticancer drugs, and is also developing medical devices. He has been involved in various domestic / international conferences members such as ASCO, ESMO and KSMO. He is working on developing new drugs through immunooncology and cancer gene analysis. 


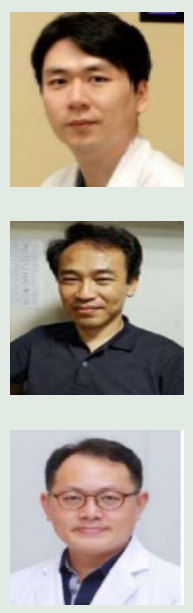

Anbok Lee M.D, Ph.D is currently an associated Professor in the Department of surgery at Inje University, Busan, South Korea. His main areas of research include research include breast cancer treatment, immunology, and biomarkers for early detection of breast cancer.

II-Whan Choi is a Professor at the College of Medicine, InJe University. His main research domain is the regulation of inflammatory response using chemical compounds and natural materials. He is also interested in the development of restorative materials for allergic diseases.

SaeGwang Park, is a Professor at the College of Medicine, INJE University. He is professor of the Postgraduate Program in Medical Science and Immunology. He has experience in the area of Cancer immunology and Immunotherapy, working mainly in: radiation therapy induced immunotherapy (Abscopal effect), Immunological cell death and recombinant protein therapeutics.

Cite this article: Quan X, Lee J, Park JH, Haque Md. M, Kim HY, Kim I, Lee A, Choi I, Park S. Induction of Triple-negative Breast Cancer Cells to Immunogenic Cell Death and Increase Cross-Presentation by Streptomyces sanyensis. Pharmacog Res. 2021;13(3):165-72. 